\title{
Identification of the 33-kDa alkaline protease of Aspergillus fumigatus in vitro and in vivo
}

\author{
M. MOUTAOUAKIL, M. MONOD*, M. C. PRÉVOST $\dagger$, J. P. BOUCHARA $\ddagger$ S. PARIS and J. P. LATGÉ
}

Unité de Mycologie, †Station Centrale de Microscopie électronique, Institut Pasteur, 25 rue du Dr Roux, 75015 Paris, France, "Service de Dermatologie, Centre Hospitalier Universitaire Vaudois, 1011 Lausanne, Switzerland and $\$$ Laboratoire de Parasitologie-Mycologie, Centre Hospitalier Universitaire, Angers, France

\begin{abstract}
Summary. Aspergillus fumigatus produced a 33-kDa serine protease (ALP) in vitro and in vivo. In vitro, this alkaline protease was secreted when the fungus was cultivated in the absence of protein, if the $\mathrm{pH}$ of the medium remained close to neutrality. Western blotting and immunoelectronmicroscopy studies showed that ALP was localised in the wall of the fungus and was degraded after secretion in the culture medium under conditions of low $\mathrm{pH}$. Although present in the lung during infection, ALP did not appear to be diagnostically useful and was different from the precipitating chymotrypsin antigen used in the diagnosis of aspergilloma.
\end{abstract}

\section{Introduction}

A $32-33-\mathrm{kDa}$ serine protease has been isolated recently from Aspergillus fumigatus by several laboratories. ${ }^{1-4}$ This alkaline protease (ALP) of the subtilisin family degrades collagen, fibrinogen and elastin. Its secretion is induced in vitro by the presence of a protein (collagen, fibrinogen, elastin, casein or liver extract) in the culture medium. ${ }^{1-4}$ It has been suggested that such extracellular proteases can play a role during the invasion of lung tissues by $A$. fumigatus or $A$. flavus $^{5-7}$ However, there is no direct evidence that the protease is secreted in vivo and is required by the fungus to invade host tissues.

The specificity of the antibody response to ALP is questionable. Antibodies were detected with high titres in the sera of only two of six patients with aspergilloma. ${ }^{1}$ In BALB/c mice, Frosco et al. ${ }^{8}$ found that ALP was weakly immunogenic whereas other authors produced monospecific rabbit polyclonal antibodies toward this protein. ${ }^{1-2}$

Western blots and immuno-electronmicroscopy were used to study ALP synthesis in vitro and in vivo. Some of the physicochemical factors involved in the secretion of ALP have been investigated. The low antigenicity of this protein has been demonstrated.

\section{Materials and methods}

\section{Strains}

A wild-type clinical isolate of $A$. fumigatus (CBS 144.89) and an alkaline protease-deficient mutant 18 (nia, alp::HPH) derived from the wild strain by genetic engineering ${ }^{9}$ were maintained on malt agar $2 \%$ slants.

\section{Human sera}

Serum samples from patients with aspergilloma, patients with candidiosis and healthy individuals were used throughout this study. Serum reactivity was monitored by both Ouchterlony diffusion assay with somatic and metabolic extracts from $A$. fumigatus (Diagnostic Pasteur, Marnes, France) and indirect haemagglutination assay (Fumouze, Clichy, France). Candidiosis patients gave negative results in all these assays. All asperigilloma patients were chymotrypsinpositive. A pool of positive human sera was prepared from 75 patients. A control pool of human sera was prepared from 50 healthy donors. Positive and negative serum pools contained equal volumes of all sera.

\section{Rabbit sera}

A monospecific rabbit antiserum directed against the $33-\mathrm{kDa}$ protease was prepared as described previously. ${ }^{2}$ A monospecific rabbit antiserum to the chymotrypsin antigen $\mathrm{C}$ or antigen 13 was kindly supplied by Dr J. Longbottom. ${ }^{10}$ Pre-immune rabbit sera were used as controls.

\section{In-vitro extracts}

For the detection of the $33-\mathrm{kDa}$ serine protease, three culture media were used: (a) Sabouraud, i.e., glucose $2 \%$ plus Mycopeptone Biokar (Prolabo, Paris) $1 \%$; (b) collagen (Serva) $0.2 \%$; (c) Mycopeptone Biokar 1\%. Conidia of A. fumigatus strain CBS 11489 were inoculated into 150 -ml Erlenmeyer flasks containing $50 \mathrm{ml}$ of Sabouraud liquid medium. Flasks were shaken for $2-3$ days at $100 \mathrm{rpm}$ and $25^{\circ} \mathrm{C}$. Twolitre Biolafitte fermenters, containing $1.2 \mathrm{~L}$ of medium, were inoculated with the medium from two shaken 
flasks (inoculum $8 \% \mathrm{v} / \mathrm{v}$ ). The culture conditions were as follows: temperature $25^{\circ} \mathrm{C}$, aeration $30 \mathrm{~L}$ of air $/ \mathrm{h}$, agitation $600 \mathrm{rpm}$, and $\mathrm{pH}$ was monitored. Fermentation experiments were also performed in Sabouraud liquid medium in fermenters with $\mathrm{pH}$ controlled at $7 \cdot 2$ throughout the duration of the culture. Strain CBS 114-89 was grown for 2-4 days depending on the culture medium. Mycelium was separated from the culture medium by paper filtration. Culture filtrate was precipitated overnight at $4^{\circ} \mathrm{C}$ by either four volumes of ethanol or ammonium sulphate dissolved in the culture filtrate to $90 \%$ saturation. The ethanol precipitate was washed twice with ethanol, resuspended in water and ultrasonicated for $3 \mathrm{~min}$. The undissolved precipitate was removed by centrifugation and the water-soluble material was kept frozen at $-20^{\circ} \mathrm{C}$. The ammonium sulphate precipitate was collected by centrifugation, resuspended in distilled water and dialysed against water for $24 \mathrm{~h}$ and $20 \mathrm{~mm}$ Tris- $\mathrm{HCl}$ buffer, $\mathrm{pH} 7 \cdot 4$, overnight at $4^{\circ} \mathrm{C}$. Preliminary experiments have shown that both techniques precipitate the $33-\mathrm{kDa}$ protease.

For the preparation of extracts containing the chymotrypsic antigen, the wild strain and the ALP ${ }^{-}$ mutant type were grown in unshaken flasks containing Sabouraud medium. After 1 month at $25^{\circ} \mathrm{C}$, mycelium was separated from the culture medium by paper filtration. Culture filtrate was concentrated by dialysis against polyethylene glycol 20000 . Concentrated culture filtrate was dialysed against distilled water and stored at $-20^{\circ} \mathrm{C}$.

\section{Mouse infection}

Male IOPS OFI mice, 20-25 g (IFFA CREDO, L'arbresle, France) were used for infection experiments. All animals were pre-treated with cortisone: $5 \mathrm{mg}$ of cortisone acetate $(200 \mu \mathrm{l}$ of a $\mathrm{NaCl} 0.9 \%$ aqueous solution containing cortisone acetate $25 \mathrm{mg}$ / $\mathrm{ml})$ were given intraperitonally 2 days before and on the day of infection. Conidia were obtained from subcultures of strain CBS 144-89 grown on malt agar $2 \%$ for $4-7$ days at $25{ }^{\circ} \mathrm{C}$. They were harvested with a $\mathrm{NaCl} 0.9 \%$ aqueous solution and counted with a haemacytometer. Mice were infected intranasally with $50 \mu \mathrm{l}$ of a conidial suspension of $A$. fumigatus $\left(10^{10}\right.$ conidia $/ \mathrm{ml}$ ) as described previously. ${ }^{11}$ Injection of this dose typically caused $100 \%$ mortality within 3 days in the infected mice. Control mice pre-treated with cortisone received intranasal injections of saline solutions. Control mice survived for at least 2 weeks after challenge.

\section{Infected lung extract}

Five lungs from infected dead mice or control mice were pooled in $0.1 \mathrm{M}$ Tris- $\mathrm{HCl}$ buffer, $\mathrm{pH} 8.4$, containing $2 \mathrm{mM}$ PMSF and homogenised in a Sorvall homogeniser for 1 or $2 \mathrm{~min}$ at $4^{\circ} \mathrm{C}$. Crude tissue homogenates were placed in a bottle with an equivalent volume of 1-mm glass beads and disrupted for 3-4 min under $\mathrm{CO}_{2}$ cooling in an MSK Braun cell disintegrator. Cell debris was removed by centrifugation $(30 \mathrm{~min}$, $15000 \mathrm{rpm}$ ). Ammonium sulphate was added to the supernate to achieve $65 \%$ saturation. After standing overnight at $4^{\circ} \mathrm{C}$, the precipitate was collected by centrifugation ( $30 \mathrm{~min}, 15000 \mathrm{rpm}$ ), resuspended in the homogenising buffer and extensively dialysed against a $2 \cdot 5 \mathrm{~mm}$ Tris- $\mathrm{HCl}$ buffer, $\mathrm{pH} 8 \cdot 4$, containing $2 \mathrm{mM}$ PMSF.

\section{Protein determination}

Protein concentration of the extracts was estimated by the BioRad method based on Coomassie Blue staining of the proteins with bovine serum albumin (BSA) as a standard.

\section{Electrophoresis and immunoblotting}

Protein extracts were submitted to SDS-PAGE according to the method of Laemmli with a separating gel of acrylamide $12 \% ;^{12} 10-25 \mu \mathrm{g}$ of protein from invitro extracts and $600-700 \mu \mathrm{g}$ of in-vivo extracts were loaded per well.

Gel contents were transferred electrophoretically on to nitrocellulose membranes $(0 \cdot 2-\mu \mathrm{m}$ pore size; Schleicher and Schuell, Ceralabo, Paris). Transfer was done in a $25 \mathrm{~mm}$ Tris- $192 \mathrm{~mm}$ glycine buffer, $\mathrm{pH} \mathrm{8.3,} \mathrm{con-}$ taining methanol $20 \% \mathrm{v} / \mathrm{v}$ at $30 \mathrm{~V}$ overnight. ${ }^{13}$ Blots were stained with Ponceau Red S $0.3 \%$ in TCA $0.3 \%$ to locate mol.-wt markers and to evaluate protein transfer. Blocking was achieved by incubation for $1 \mathrm{~h}$ at room temperature in phosphate buffered saline (PBS) containing Tween $200 \cdot 15 \% \mathrm{v} / \mathrm{v}$ (PBST) and non-fat dried milk (Regilait) $5 \% \mathrm{w} / \mathrm{v}$ (PBSTM). The antigenic reactivity was determined by incubation of nitrocellulose strips with transblotted material in PBSTM containing rabbit antisera at a 1 in 1000 dilution (and 1 in 100 in the case of anti-Ag13 antiserum) or human sera at a 1 in 500 dilution for $1 \mathrm{~h}$ at room temperature. In the case of in-vitro extracts, sites of binding of antibodies were determined by incubation of the blot in a peroxidase-conjugated goat anti-rabbit or anti-human $\operatorname{IgG}(\mathrm{H}+\mathrm{L})$ diluted at 1 in 1000 in PBST. Development was performed with 33 'diaminobenzidine (DAB) in PBS containing DAB $0.04 \%$ plus $\mathrm{H}_{2} \mathrm{O}_{2} 0.015 \%$. For in-vivo extracts, DAB development was negative due to the low amount of antigens present in the lung. Intensification of the reaction was achieved with an enhanced chemiluminescence Western blotting detection system (ECL kit, Amersham). For this method, blocking was achieved by incubation for $1 \mathrm{~h}$ at $37^{\circ} \mathrm{C}$ in $0.1 \mathrm{M}$ Tris, $\mathrm{pH} 8.0$, containing $15 \mathrm{~mm} \mathrm{NaCl}, 1 \mathrm{~mm}$ EDTA, Tween 20 $0.05 \%$ (TBST) and non-fat milk $10 \%$. Rabbit antibody and peroxidase-conjugated goat anti-rabbit IgG $(\mathrm{H}+\mathrm{L})$ were diluted to 1 in 500 and 1 in 20000, respectively, in the same buffer. Final washings were 
done with three rinses of TBST and two rinses of $0 \cdot 1 \mathrm{M}$ Tris, $\mathrm{pH} 8 \cdot 0$, containing $15 \mathrm{~mm} \mathrm{NaCl}$. Development was performed for $30 \mathrm{~s}$.

\section{Counterimmuno-electrophoresis}

Counterimmuno-electrophoresis was performed on a cellulose acetate membrane (Sartorius, 11200-25-160 IEN) basically as described previously. ${ }^{14}$ Serum $(15 \mu \mathrm{l})$ from a pool of aspergilloma patients was deposited towards the anode whereas the antigen from wild-type and mutant strains ( $15 \mu \mathrm{l}$ at $1-1.5 \mathrm{mg}$ protein $/ \mathrm{ml}$ ) was deposited at the cathode. Migration buffer was $50 \mathrm{~mm}$ Tris-glycine, $\mathrm{pH} 8.8$. After electrophoresis for $2 \mathrm{~h}$ at $100 \mathrm{~V}$, membranes were washed in a $\mathrm{NaCl} 0.85 \%$ solution. Chymotrypsin activity was localised in precipitin arcs by use of $\mathrm{N}$-acetyl-DL phenyl alanine $\beta$ naphthyl ester as a substrate. ${ }^{15}$

\section{Immunofluorescence}

Lungs were fixed overnight at $4^{\circ} \mathrm{C}$ in formaldehyde $10 \%$ aqueous solution ( $40 \mathrm{vol}$, Labo Nord, Villeneuve d'Ascq, France) and embedded in paraffin after dehydration with increasing concentrations of ethanol and a final rinse in toluene. After removal of the paraffin, tissue sections $(5 \mu \mathrm{m})$ were incubated with rabbit anti-ALP serum diluted 1 in 100 in PBS for $30 \mathrm{~min}$ at $37^{\circ} \mathrm{C}$. The sections were washed extensively in PBS, and then incubated with anti-rabbit immunoglobulin-fluorescein conjugate (Institut Pasteur Production) diluted 100-fold in the same buffer. Before fluorescence microscopy, the tissue sections were stained with Evans blue diluted 1 in 10000 in water. The same experiment was done with a preimmune rabbit serum as control.

\section{Immuno-electronmicroscopy}

An infected lung was fixed for $1 \mathrm{~h}$ at room temperature, trimmed in $5 \times 5-\mathrm{mm}$ blocks and post-fixed overnight at $4^{\circ} \mathrm{C}$ in a solution containing formaldehyde $2.5 \% \mathrm{v} / \mathrm{v}$, glutaraldehyde $0.5 \% \mathrm{v} / \mathrm{v}$ in a sodium cacodylate buffer, $\mathrm{pH} 7 \cdot 2$. After incubation for $12 \mathrm{~h}$ in the cacodylate buffer containing $0.01 \mathrm{M}$ ammonium chloride material was dehydrated with increasing concentrations of ethanol and embedded in LR White resin as described by Newman and White at room temperature. ${ }^{16}$ Ultra-thin sections recovered on formvar-coated grids were incubated for $1 \mathrm{~h}$ at room temperature with anti-ALP anti-serum diluted 1 in 100 and 1 in 500 in PBS, pH 7.2, containing BSA $1 \% \mathrm{w} / \mathrm{v}$ and subsequently washed in the same buffer containing BSA $0 \cdot 1 \% \mathrm{w} / \mathrm{v}$. Sections were then incubated with gold-labelled anti-IgG conjugate $(10 \mathrm{~nm}$; Janssen, France) diluted 1 in 50 in PBS with BSA $1 \%$. After $1 \mathrm{~h}$ at room temperature, sections were washed three times with PBS with BSA $0.1 \%$, twice with PBS and five times with water. A pre-immune rabbit serum was used as control.

\section{Results}

\section{Secretion of $A L P$ in vitro}

Immunoblot analysis with the monospecific antiALP rabbit antiserum demonstrated that ALP was present in the culture filtrate of three media: collagen $0.2 \%$, mycopeptone $1 \%$ and Sabouraud medium with pH controlled at $7 \cdot 2$ (fig. 1). ALP was not detected in the culture filtrate of Sabouraud medium. The change in $\mathrm{pH}$ in Sabouraud medium, collagen medium and peptone medium is shown in fig. 2. Conversely, in collagen $0.2 \%$ and mycopeptone $1 \%$ medium where

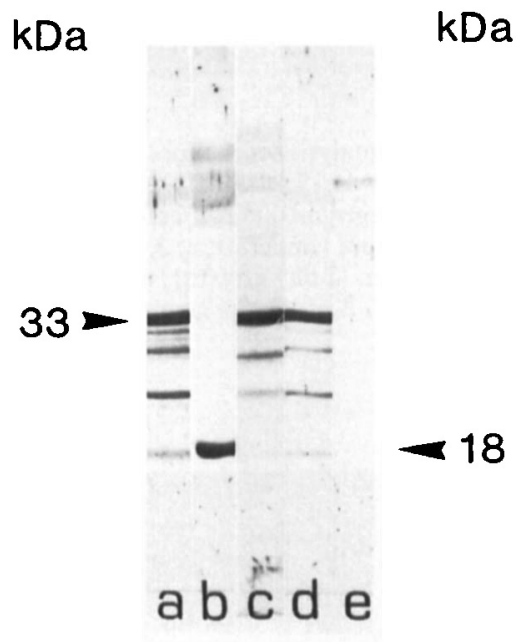

Fig. 1. Immunoblot analysis of culture filtrate extracts from different media: lanes a and e, collagen $0.2 \%$; b, Sabouraud medium without $\mathrm{pH}$ control; c, Sabouraud medium with $\mathrm{pH}$ controlled at 7.2 ; d, mycopeptone $1 \%$. Blots were probed with a 1 in 500 dilution of the anti-ALP rabbit antiserum (a-d) and a pre-immune rabbit serum (e).

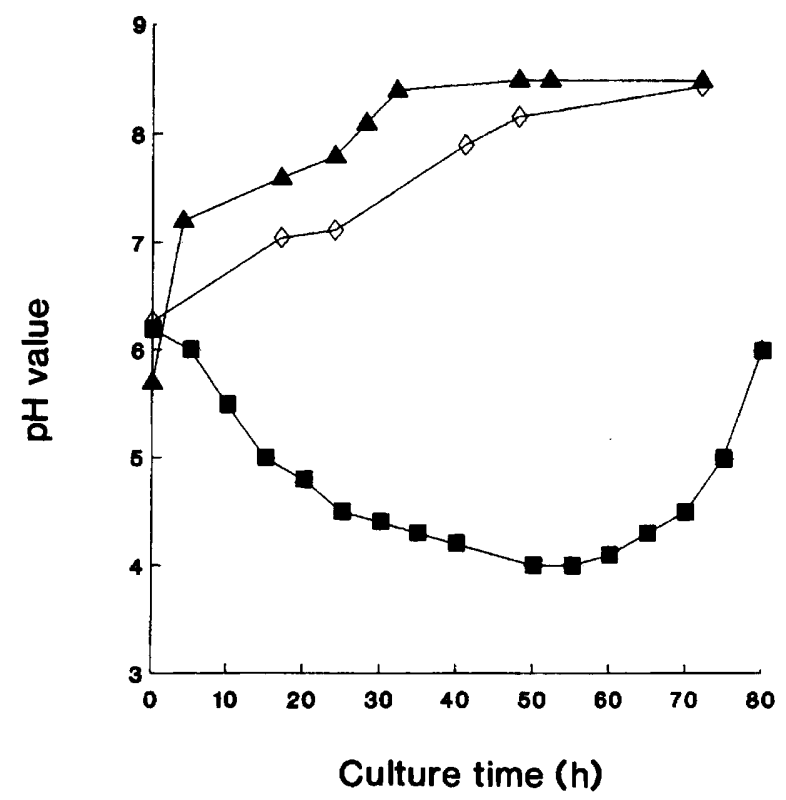

Fig. 2. $\mathrm{pH}$ kinetics in three different liquid inoculated with $A$. fumigatus: Sabouraud $\mathbf{D}$; collagen $0.2 \% \boldsymbol{\Delta}$; mycopeptone $1 \% \diamond$. 


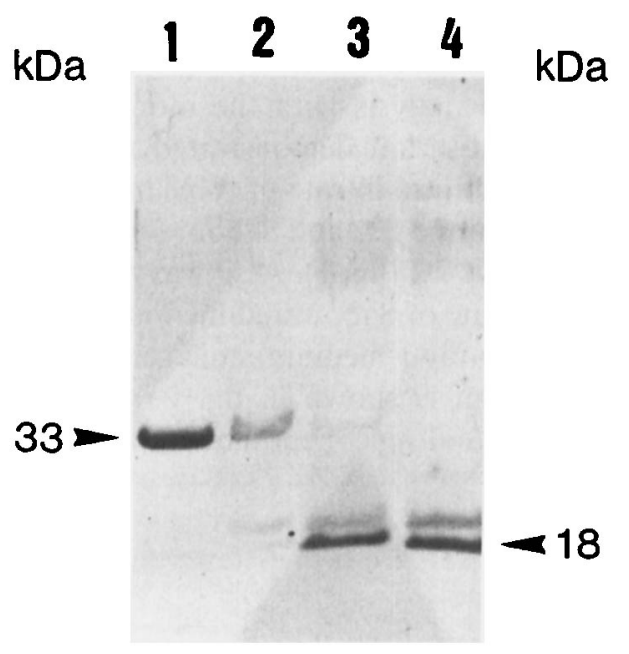

Fig. 3. Immunoblot analysis of culture filtrate extracts of $A$. fumigatus strain CBS 144.89 probed with an anti-33 kDa ALP antiserum. Lane 1, collagen medium; 2 , collagen medium incubated at $\mathrm{pH} 4.5$ for $24 \mathrm{~h}$ at room temperature; 3 , collagen medium mixed with Sabouraud medium (2 day growth); 4, Sabouraud medium (2 day growth).

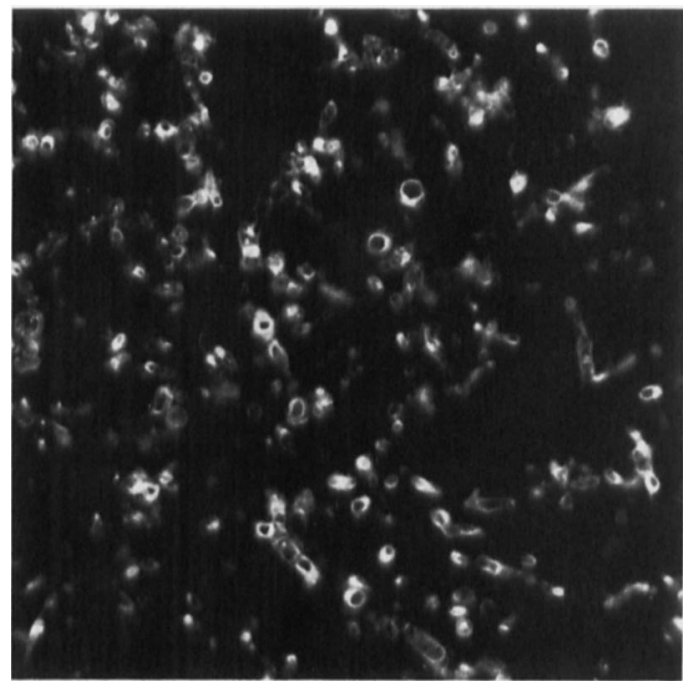

Fig. 4. Reactivity of mycelia in the lung of an immunocompromised mouse infected with $A$. fumigatus. Indirect immunofluorescence was achieved with anti-ALP rabbit antiserum diluted 1 in 100 and fluoresceinylated anti-rabbit IgG antiserum diluted 1 in 100 .

the $\mathrm{pH}$ remained slightly basic, a significant decrease in the $\mathrm{pH}$ of the medium was observed during mycelial growth in Sabouraud medium. Adjustment of the $\mathrm{pH}$ of a culture filtrate from collagen medium, containing ALP, to a value of 4.5 (similar to the $\mathrm{pH}$ found in Sabouraud medium at maximal growth) resulted in the disappearance of the 33-kDa protease after $24 \mathrm{~h}$ at room temperature. The 33-kDa ALP was still detected in control culture filtrate ( $\mathrm{pH} \mathrm{7.5)} \mathrm{left} \mathrm{for} 24 \mathrm{~h}$ at room temperature. Moreover, co-incubation for $24 \mathrm{~h}$ at room temperature of equal volumes of a collagen

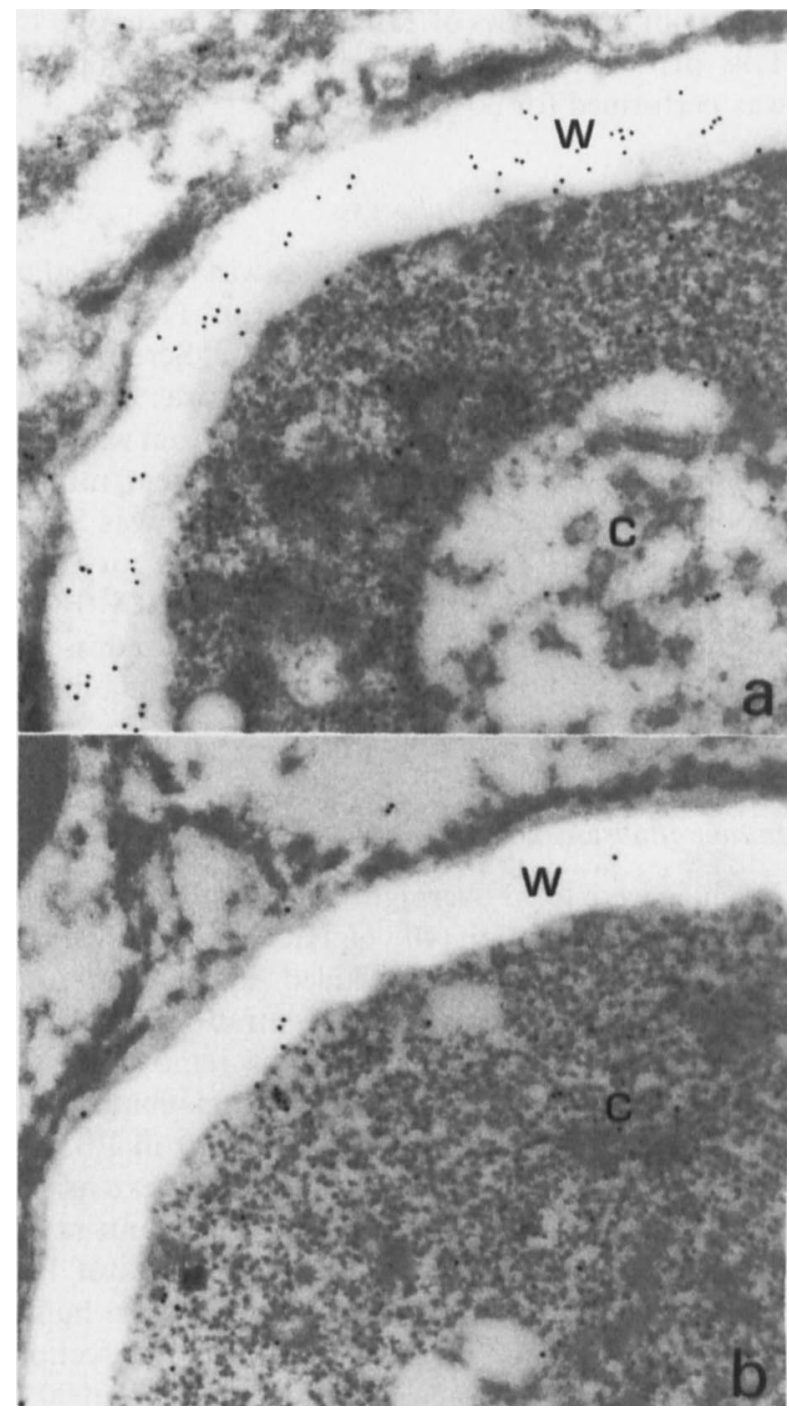

Fig. 5. Reactivity of the anti-ALP antiserum with the wall of a hyphal element in the lung of an infected mouse. (a) Anti-ALP and (b) pre-immune sera were diluted 1 in 500 and anti-rabbit IgG immunoglobulin conjugated to colloidal gold $(10 \mathrm{~nm})$ was diluted 1 in 40 . w, mycelial wall; c, cytoplasm $(\times 51000)$.

culture filtrate which contained the $33-\mathrm{kDa}$ protease, and a Sabouraud medium culture filtrate at $\mathrm{pH} 4.7$ (2 days of growth), also induced the disappearance of the $33-\mathrm{kDa}$ protease (fig. 3). Secretion of ALP was also demonstrated by immunofluorescence on germ tubes developed after incubation of conidia overnight at $37^{\circ} \mathrm{C}$ in Sabouraud medium, during a period of time where no decrease in $\mathrm{pH}$ was observed (data not shown). The 33-kDa serine protease was degraded by acid $\mathrm{pH}$ and the low molecular mass $(18 \mathrm{kDa})$ immunoreactive band found in Sabouraud medium represented an ALP breakdown product. ALP was also secreted in a yeast extract $1 \%$ medium or in a medium containing glucose $2 \%$, asparagine $0.5 \%$ and a salt solution (data not shown). The secretion of ALP in the protein hydrolysate media (which do not contain protein as shown by SDS-PAGE) and in the asparagine-based medium showed that the presence of a protein in the culture medium was not necessary to induce the secretion of ALP. The requirement of a 


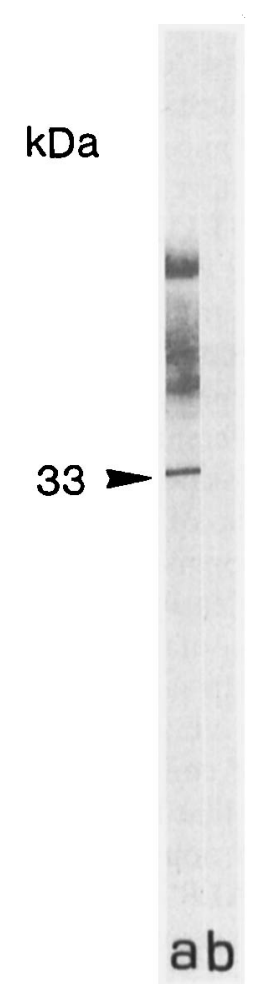

Fig. 6. Immunoblot analysis of a total lung extract from an infected mouse. Blots were probed with a 1 in 500 dilution of: a, anti-ALP antiserum; b, a pre-immune serum.
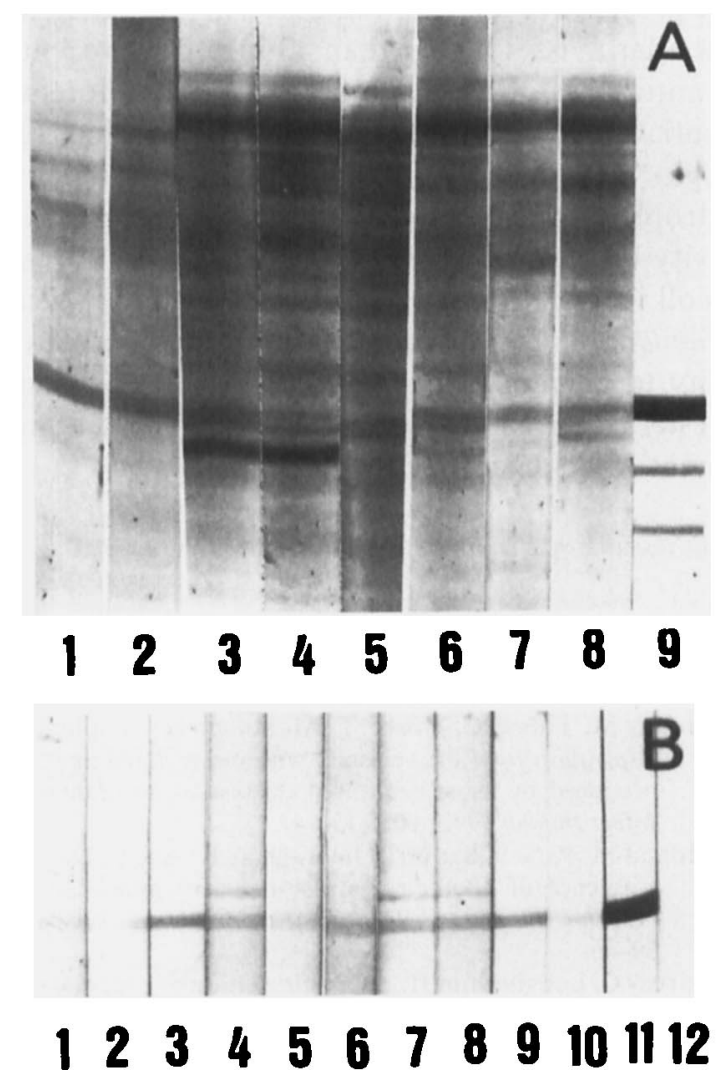

Fig. 7. Immunoblot analysis of culture filtrate from collagen medium (panel A) and a purified 33-kDa ALP (panel B) probed with sera diluted 1 in 500 from aspergilloma patients (Panel A, lanes 3-8; panel B, lanes 5-10) and candidiosis patients (Panel A, lanes 1,2; panel B, lanes 1-4). Lanes A9 and B11 were incubated with rabbit anti-ALP antiserum diluted 1 in 1000 and lane B12 with a preimmune rabbit serum at the same dilution.

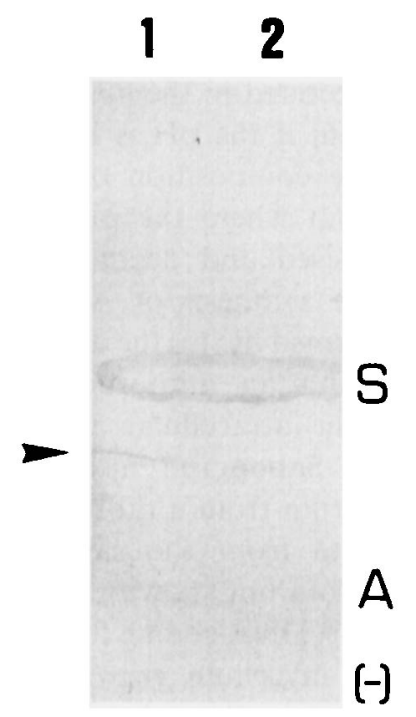

Fig. 8. Detection by counterimmuno-electrophoresis of a chymotrypsic precipitin arc $(>)$ in the culture filtrate of : $1, \mathrm{ALP}^{-}$mutant strain; 2, wild-type strain. $\mathrm{S}$, human serum pool; $\mathrm{A}$, antigen; cathode.

slightly basic environment, similar to $\mathrm{pH}$ found in human biological fluids, to maintain the integrity of this protease, prompted us to investigate the presence of ALP in vivo.

\section{Presence of ALP in vivo}

Indirect immunofluorescence studies showed that anti-ALP rabbit antiserum labelled mycelium in the lungs of infected mice. Binding of immunoglobulin was predominantly to the wall of fungal cells. No labelling was seen with pre-immune rabbit serum by either immunofluorescence or immuno-electronmicroscopy (figs. 4 and 5).

The presence of ALP in the lungs of infected mice was confirmed by Western blots of infected lung extracts (fig. 6).

In Western blots, ALP did not discriminate between samples from aspergilloma patients and other patients not suffering from aspergilloma. Amongst 29 sera tested, 25 labelled the 33-kDa ALP at a 1 in 500 dilution. No difference was seen between the $A$. fumigatus positive patients ( 17 of 21 ) and eight negative patients (fig. 7).

The anti-Ag 13 rabbit antiserum did not react with the $33-\mathrm{kDa}$ protein even at 1 in 100 dilution (although at a 1 in 1000 dilution it bound strongly to a high mol. wt antigen in the collagen extract). Moreover, counterimmuno-electrophoresis of a pool of patients and culture filtrate extracts from the wild strain and a $33-\mathrm{kDa}$ protease-deficient mutant was positive for chymotrypsin antibody in both extracts (fig. 8).

\section{Discussion}

Previous work has shown that the alkaline protease from $A$. fumigatus is secreted in media containing a protein source..$^{1-4}$ Northern blot experiments have shown that the synthesis of ALP was highly stimulated 
if a protein such as collagen was present in the culture medium. ${ }^{17}$ Our results showed that ALP can still be synthesised and secreted in the absence of protein in the culture medium if the $\mathrm{pH}$ is held slightly basic, irrespective of the composition of the medium. In Sabouraud medium where the $\mathrm{pH}$ becomes acidic, ALP was synthesised and degraded due to acidic conditions. Active synthesis of ALP in Sabouraud medium was confirmed by: (a) the detection of ALP by Western blot using an antiserum from a rabbit immunised with an intracellular extract from a mycelium grown in Sabouraud medium for 2 days, whereas an antiserum from a rabbit immunised with the culture filtrate from the same medium gave negative results (data not shown); and (b) the identification of specific cDNA coding for ALP in a library constructed from mycelium grown for 4 days in a Sabouraud medium. ${ }^{17}$ Battaglino et al. have also demonstrated that the production of the alkaline protease from $A$, oryzae, which is highly related to the one produced by $A$. fumigatus ${ }^{2}$ is highly reduced by low $\mathrm{pH}^{18}$ These authors stated that the $\mathrm{pH}$ of the culture medium must be maintained over 6.5 for a high protease yield. Although Reichard et al. did not mention the role of $\mathrm{pH}$ during secretion of the enzymes, their data showed that the decrease of $\mathrm{pH}$ during growth is correlated with a decrease in the proteolytic activity of the culture filtrate. ${ }^{1}$

The human pathogens $A$. flavus and A. fumigatus, like most members of the genus Aspergillus, produce high amounts of proteases of different classes in vitro: serine protease, aspartyl proteases, metalloproteases. ${ }^{1,2,19-21}$ A limited number of studies have suggested that in the genus Aspergillus, as in the genus Candida, proteases may be essential virulence determinants. This study presents immunochemical and cytological evidence that the major $32-33 \mathrm{kDa}$ protease of $A$. fumigatus is indeed secreted in vivo. It confirmed previous observations by Reichard et al. ${ }^{1}$ who showed that the $32-\mathrm{kDa}$ protease they studied was also detectable by immunofluorescence in the lung of experimentally infected guinea-pig. ${ }^{1}$ However, the

\section{References}

1. Reichard U, Büttner S, Eiffert H, Staib F, Rüchel R. Purification and characterisation of an extracellular serine proteinase from Aspergillus fumigatus and its detection in tissue. $J$ Med Microbiol 1990; 33: 243-251.

2. Monod M, Togni G, Rahalison L, Frenk E. Isolation and characterisation of extracellular alkaline protease of $A s$ pergillus fumigatus. J Med Microbiol 1991; 35: 23-28.

3. Bouchara JP, Larcher G, Annaix V et al. Fibrinogenolytic activity of Aspergillus fumigatus culture filtrate. $J$ Mycol Med 1991; 1: 105-111.

4. Frosco M, Chase T, McMillan JD. Purification and properties of the elastase from Aspergillus fumigatus. Infect Immun 1992; 60: 728-734.

5. Miyaji M, Nishimura K. Relationship between proteolytic activity of Aspergillus fumigatus and the fungus invasiveness of mouse brain. Mycopathologia 1977; 62: 161-166.

6. Kothary MH, Chase T, McMillan JD. Correlation of elastase production by some strains of Aspergillus fumigatus with ability to cause pulmonary invasive aspergillosis in mice. Infect Immun 1984; 43: 320-325. role of this protease during the infection process remains an open question since $\mathrm{ALP}^{-}$mutants were still pathogenic for mice. ${ }^{9}$

Reichard et al. have detected high titres of antibodies against the 33-kDa ALP in some aspergilloma patients by ELISA. ${ }^{1}$ With Western blotting assays, we have shown that anti-33-kDa antibodies did not discriminate between aspergilloma and candidiosis patients. The discrepancy between these results could be due to the different immunoassays used. With different purified 33-kDa ALP batches, we have found that trace amounts of high mol.-wt. proteins not detectable by Coomassie Blue staining but very immunogenic and easily seen by Western blotting experiments, can contaminate purified fractions of ALP and give rise to false positive results in ELISA (unpublished observations).

The reactivity of control sera against the $33-\mathrm{kDa}$ protease suggested that this protease may share common epitopes with non-Aspergillus proteins. By the combined use of ALP $^{-}$mutant and a monospecific antiserum directed against the chymotrypsin antigen it was shown that the $33-\mathrm{kDa}$ protease is different from the "chymotrypsin" antigen $(=\mathrm{AgC}=\mathrm{Ag} 13)$ which is used in the diagnosis of aspergilloma. This antigen is a high mol.-wt, glycosylated (ConA positive) molecule. The absence of cross-reactivity of anti-antigen 13 antiserum with the $33-\mathrm{kDa}$ protease is in agreement with previous results stating that only antigens with molecular masses higher than $43 \mathrm{kDa}$ can precipitate the antibodies of aspergilloma patients. ${ }^{10}$ Moreover, somatic antigens from Diagnostics Pasteur which have a high "chymotrypsin" activity in counterimmunoelectrophoresis have a very low azocoll degradation activity (data not shown) whereas ALP degrades azocoll very efficiently. ${ }^{2}$ The chymotrypsin antigen of $A$. fumigatus has been identified until now only by its ability to degrade $\mathrm{N}$-acetyl-DL-phenylalanin $\beta$ naphtyl ester. The nature of this chymotrypsin antigen remains to be determined.

This research was supported by INSERM grant 900313 .

7. Rhodes JC, Bode RB, McCuan-Kirsch CM. Elastase production in clinical isolates of Aspergillus. Diagn Microbiol Infect Dis 1988; 10: 165-170.

8. Frosco M, Fahed C, Chase T, McMillan JD. Inhibition of Aspergillus fumigatus elastase with monoclonal antibodies produced by using denatured elastase as an immunogen. Infect Immun 1992; 60: 735-741.

9. Monod M, Paris S, Sarfati J, Jaton-Ogay K, Ave P, Latgé J-P Virulence of alkaline protease-deficient mutants of Aspergillus fumigatus. FEMS Microbiol Lett 1993; 106: 39-46.

10. Harvey C, Longbottom JL. Characterization of a second major antigen $\mathrm{Ag} 13$ (antigen $\mathrm{C}$ ) of Aspergillus fumigatus and investigation of its immunological reactivity. Clin Exp Immunol 1987; 70: 247-254.

11. Dixon DM, Polak A, Walsh TJ. Fungus dose-dependent primary pulmonary aspergillosis in immunosuppressed mice. Infect Immun 1989; 57: 1452-1456.

12. Laemmli UK. Cleavage of structural proteins during the assembly of the head of bacteriophage T4. Nature 1970; 227: 680-685.

13. Towbin H, Staehelin T, Gordon J. Electrophoretic transfer of 
proteins from polyacrylamide gels to nitrocellulose sheets: procedure and some applications. Proc Natl Acad Sci USA $1979 ; 76: 4350-4354$.

14. Poulain D; Fruit J, Fournier L, Dei Cas E, Vernes A. Diagnosis of systemic candidiasis. Application of co-counterimmunoelectrophoresis. Eur J Clin Microbiol 1986; 5: 427-434.

15. Biguet J, Tran van Ky P, Fruit J, Andrieu S. Identification d'une activité chymotrypsique au niveau de fractions remarquables d' Aspergillus fumigatus. Répercussions sur le diagnostic immunologique de l' aspergillose. Rev Immunol Paris 1967; 31: 317-328.

16. Newman GR, White LR. Embedding medium for colloidal gold methods. In: Hayat MA (ed) Colloidal gold. Principles, methods and application. San Diego, Academic Press. 1989: 47-73.

17. Jaton-Ogay K, Suter M, Crameri R, Falchetto R, Fatih A, Monod M. Nucleotide sequence of a genomic and a cDNA clone encoding an extracellular alkaline protease of $A s-$ pergillus fumigatus. FEMS Microbiol Lett 1992; 92: 163-168.

18. Battaglino RA, Huergo M, Pilosof AMR, Bartholomai GB. Culture requirements for production of protease by $A s$ pergillus oryzae in solid state fermentation. Appl Microbiol Biotechnol 1991; 35: 292-296.

19. Rhodes J, Amlung TW, Miller MS. Isolation and characterization of an elastinolytic proteinase from Aspergillus flavus. Infect Immun 1990; 58: 2529-2534.

20. Panneerselvam M, Dhar SC. Physico-chemical properties of the acid proteinase from Aspergillus fumigatus. Ital J Biochem $1981 ; 30: 63-74$.

21. Zhu WS, Wojdyla K, Donlon K, Thomas PA, Eberle HI. Extracellular proteases of Aspergillus flavus. Fungal keratitis, proteases, and pathogenesis. Diagn Microbiol Infect Dis $1990 ; 13$ : 491-497.

J. Med. Microbiol. - Vol. 39 (1993), 399-400

(c) 1993 The Pathological Society of Great Britain and Ireland

\title{
ANNOUNCEMENTS
}

\author{
The Royal College of Pathologists \\ One-day Symposium
}

Diagnostic Coding and Disease Classification

Thursday 2nd December 1993 to be held at the Royal College of Pathologists, 2 Carlton House Terrace, London SW1Y 5AF

\section{Provisional programme}

Chairman: Professor P. G. Toner (Queen's University of Belfast); Introduction; ICD-The original international classification for health care statistics, Speaker from WHO, Geneva (Name to be confirmed); Read codes-The standard coded thesaurus of clinical terms for the NHS, Dr C. Stuart-Buttle (NHS Centre for Coding and Classification, Loughborough); SNOMED International-The most comprehensive system for medical information management, Professor Roger Cote (Chairman, SNOMED International Editorial Board). Lunch (Refreshments provided).

Current Developments in OPCS Mortality Coding, Dr Cleo Rooney (Office of Population Censuses and Surveys, London); Coding, Classification and the National I M \& T Strategy, Mr Ian Smith (Director of Strategic Planning, Information Management Group, NHS Management Executive, Leeds); The way forward, General discussion and questions; Demonstrations

The symposium is open to members of the College, to trainee pathologists and to workers in other disciplines with an interest in the subject. The programme is approved by the Thames Postgraduate Deans and hospital doctors may apply to their employing authority for Study Leave under $\mathrm{HM}(67) 27$.

The registration fee is $£ 94$ and includes coffee, lunch and tea.

Details and application forms may be obtained from: Maureen Russell, Royal College of Pathologists, 2 Carlton House Terrace, London SW1Y 5AF, Tel: 0719305862 (Ext: 24/26). 